\title{
Emerging Infectious Agents and Blood Safety in Latin America
}

\author{
José Eduardo Levi* \\ Hospital Israelita Albert Einstein, São Paulo, Brazil
}

Historically, emerging infectious agents have been an important driving force toward the enhancement of blood safety, illustrated by the sharp reduction in the transmission of infectious agents by blood transfusion after human immunodeficiency virus (HIV) epidemics. In general, Latin American (LATAM) countries have introduced screening for microorganisms with proven blood transmission with some delay in comparison to developed countries, but, nowadays, all LATAM countries comply with a minimum standard of screening which includes Hepatitis B, C, HIV, Treponema pallidum, and Trypanosoma cruzi. Noticeably, all those agents, in addition to HTLV, cause chronic infections. By contrast, in the last decade, the region has witnessed explosive outbreaks of arboviral diseases, representing a new challenge to the blood system, threatening not only blood safety but also availability. So far, the clinical impact of transfusion-transmitted Dengue, Chikungunya, or Zika has not been evident, precluding immediate reaction from the authorities. A number of other arboviruses are endemic in the region and may, unpredictably, originate new epidemics. Several measures must be taken in preparedness for the potential emergence of another arbodisease.

Christoph Niederhauser, Transfusion Interrégionale CRS SA, Switzerland

Reviewed by: Anastasios G. Kriebardis, Technological Educational Institute of Athens, Greece

Thierry Burnouf,

Taipei Medical University,

Taiwan

${ }^{*}$ Correspondence: José Eduardo Levi jose.levi@einstein.br

Specialty section:

This article was submitted to Hematology,

a section of the journal

Frontiers in Medicine

Received: 12 January 2018 Accepted: 01 March 2018

Published: 14 March 2018

Citation:

Levi JE (2018) Emerging Infectious Agents and Blood Safety in Latin America. Front. Med. 5:71. doi: 10.3389/fmed.2018.00071
Keywords: blood transfusion, arboviruses, Latin America, Zika, Dengue, Chikungunya

\section{INTRODUCTION}

The first agent verified to be transmitted by blood transfusion was the malaria protozoa (1) followed by Syphilis, the latter leading to the introduction of predonation testing in the first decades of the previous century (2). During the next 70 years, the safety of blood transfusions was gradually increased, covering a growing range of agents, more importantly the hepatitis viruses and human immunodeficiency virus (HIV). In common, all these pathologies have a short symptomatic acute phase and a variable rate of progression to a chronic asymptomatic period that may last through life. Blood units collected from unaware infected donors are averted from being transfused by detecting specific antibodies against those agents. With the exception of the hepatitis B virus (HBV) surface antigen (HBsAg) detection, the hallmark of prevention by laboratorial analysis has been the development and implementation of imunoassays, including, in some countries, the anti-hepatitis B core antigen (anti-HBc), that detects occult B carriers lacking, by definition, detectable HBsAg.

By the beginning of the millennia, the evolution of nucleic acid testing (NAT) allowed their incorporation to the blood screening routine, in order to interdict window-period donations, pursuing for an unattainable zero risk. A better selection of candidate donors with more stringent epidemiological and behavioral restrictions, summed to the arsenal of screening tests, have dropped the risk of transfusion transmission of infectious agents to a very low level, being nowadays a rare event (3). 
Latin American (LATAM) countries are in general still struggling to motivate the population to donate blood voluntarily and regularly. Donations in the region are commonly insufficient for sustaining the transfusion demand, thereby resulting in a permanent blood shortage. In many countries, most of the donations come from replacement, often familiar donors (4) and emphasis is given to transform those into altruistic regular donors. Surprisingly, it has been observed that in some centers, repeat donors pose a risk that is similar or even higher than firsttime donors concerning HIV transmission (5). This observation is justified by a fraction of repeat donors being indeed composed of HIV test seekers (6).

With some delay in comparison to developed countries, the four most important screening targets, HBV, HCV, HIV, and Syphillis, in addition to Trypanosoma cruzi, of local uttermost importance, were fully implemented in the 1990s (4). Seroprevalence of these agents were and are still much higher when compared to those verified in blood donors from Europe, Japan, Canada, and the US $(3,4,7)$.

In this scenario, the explosive outbreaks of arboviruses with a high rate of asymptomatic subjects with a short-term viremia is new to the LATAM blood transfusion community; thus, there is a lot of uncertainty in how to deal with it. There are several proposed measures to mitigate this situation: averting blood collection in affected regions, applying pathogen reduction methods for plasma and platelet concentrates, adopting NAT and quarantine while waiting for post-donation information of donor's health. Some countries may implement all them and others one or none. Certainly, this variability is not only due to scientific gaps in our knowledge but also to the resources available and political determination in each country or region. Table 1 summarizes selected features of the arboviruses representing today potential threats to the blood supply in LATAM.

\section{EMERGING VIRUSES}

\section{Dengue}

Viruses transmitted by arthropods (arboviruses) have always been of concern to human health but never much in the radar of blood banks. Dengue was the first arbovirus to cause epidemics in a global scale in the twenty-first century, globally affecting

TABLE 1 | Selected features of emerging viruses representing a potential threat to the blood supply in Latin America, 2018.

\begin{tabular}{lccc}
\hline & \multicolumn{3}{c}{ Arbovirus } \\
\cline { 2 - 4 } & Chikungunya & Dengue & Zika \\
\hline Family/genus & Togaviridae/ & Flaviviridae/ & Flaviviridae/ \\
& alphavirus & flavivirus & flavivirus \\
Enveloped & Yes & Yes & Yes \\
Viremic blood donors & Yes & Yes & Yes \\
Proven TT & No & Yes & Yes \\
NAT screening commercially & No & No & Yes \\
available & & & Yes \\
Inactivated by PITa & Yes & Yes & No \\
Vaccine available & No & Yes & \\
\hline
\end{tabular}

aPathogen reduction/inactivation technologies. millions, from the Far East to the Americas. In LATAM, Brazil has been the country with the largest number of cases, experiencing yearly outbreaks from moderate to high intensity. Moreover, all four serotypes are now endemic, but there is still a large number of subjects naïve to at least one of the four serotypes, meaning that outbreaks will continue to occur.

The main impact of dengue outbreaks to the blood system is the fall in the number of candidate donors, thus shortening the supply of blood products, aggravated by the universal practice of transfusing dengue patients with low platelet counts (8). As most dengue infections are asymptomatic, it is likely that such infected subjects are be able to donate and thus eventually transmit the dengue virus to recipients. This possibility was demonstrated by several studies detecting viremic donors in Brazil (9-11), Honduras (9), Mexico (12), and Puerto Rico (13) among others.

However, there is an obvious discrepancy in between the dengue incidence and rates of viremia verified among blood donors during outbreaks and the paucity of reports of dengue cases by the transfusional route (TT-DENV). The most comprehensive study on TT-DENV showed that recipients have an approximately $36 \%$ risk to get the virus from a viremic donor, but was unable to depict dengue-specific symptoms on those infected (11). Several reasons have been presented to explain this (un)finding, discussed in detail elsewhere (14), but may be summarized as follows: it seems that dengue viruses are well adapted to the mosquito to human cycle, and, passage through the invertebrate host and inoculation by its bite are required to cause disease on us. So, although TT-DENV is a recognized risk in many endemic countries in LATAM, preventive measures were never taken, since it did not convince clinicians and authorities of its morbidity for recipients. However, it is necessary to emphasize that, in rare instances, severe dengue-associated symptoms were observed on recipients of viremic donations $(13,15)$, thereby leading to the implementation of laboratorial screening in Puerto Rico, first by using NS1 antigen testing further replaced by NAT (16) but in nowhere else in LATAM.

\section{West Nile Virus (WNV)}

The diverse outcome of the different Flaviviruses causing human diseases requires that each viral species to be studied in depth, making analogies and generic Flavivirus models of little practical utility. This was well illustrated when the WNV arrived to the US by the end of the previous century. It took about 2 years to get enough evidence of its aggressiveness when acquired by blood transfusion or organ transplantation (17), since there was no previous recognition of any arbovirus transmission by these modes. When this link was unquestionably proven, it triggered a fast response from the transfusion medicine community, culminating in the introduction of screening by NAT (18). As WNV moved so fast from East to West US, it seemed inevitable that it would spread further South to LATAM, since susceptible vectors are abundant in the region and there is a huge migration of bird species that may harbor high titer viremias, from US and Canada to South America. Contrary to expectations, WNV was never able to cause human outbreaks in LATAM (19). 


\section{Zika}

The trajectory of Zika virus (ZKV) from an obscure agent to a global health emergence has been comprehensively described (20). The well-studied outbreak in French Polynesia revealed the important association of ZKV to Guillain-Barré syndrome (21), while Brazil was the country to raise and prove the hypothesis of a shocking causal association of this Flavivirus to microcephaly and other fetal neural abnormalities (22). Concerns about blood safety were raised by Musso and co-workers in French Polynesia where NAT, pathogen inactivation and quarantine were deployed to protect the blood supply (23). So far, there are only two published clusters of TT-ZKV, both from Brazil $(24,25)$. Similar to TT-DENV, on those reports it was shown that ZKV was indeed transmitted to transfusion recipients but they did not develop any symptom associated with Zika disease. In French Polynesia, look-back of 12 recipients transfused with red blood cells from $\mathrm{ZKV} \mathrm{RNA}^{+}$donors has not also identified any post-transfusion symptoms (23). Even though solid evidence for a severe clinical outcome of TT-ZKV is still missing, the precautionary principle led Fundação Pró-Sangue/Hemocentro de São Paulo, Brazil, to develop a validated in-house NAT (26) and adopt it, from February 2016 on, to provide Zika-RNA-free blood units to approximately 20 pregnant women per month. In Martinique, Guadaloupe, and the French Guyana, pregnant women received blood collected in mainland France (Xavier de Lamballerie, personal communication) while donations were screened by individual NAT in Marseille, France (27). This policy of prioritizing groups at higher risk such as pregnant and highly transfused fertile women, and fetuses was further advocated by experts and organizations in the field (28) and WHO (29). In the US, in observation of FDA recommendations, blood collection was halted in Puerto Rico in between March and April 2016, resumed when NAT screening was introduced in late April. Approximately $0.5 \%$ of the donors were found viremic, peaking to $1.8 \%$ in July 2016 (30). Mosquito-borne and travel-associated cases in the continental US led the FDA to extend the recommendation of NAT screening to the whole country, being implemented by September/October 2016 and indeed depicting some infected donors, the majority with a recent travel history to an endemic area $(31,32)$. No country in LATAM so far followed this policy. The sharp decline in Zika incidence in LATAM in 2017 reduced the pressure and debate over this issue. High seroprevalence rates are observed today in the most affected areas of Brazil, what may prevent new large outbreaks in the near future $(22,33)$.

\section{Chikungunya}

Chikungunya (CHKV), in common with Zika and Dengue, is also transmitted by mosquitos from the Aedes genus, causing similar symptoms, making difficult to perform a diagnosis relying solely on clinical manifestations. Noticeably, arthralgia is much more pronounced and may last for months in some patients.

Its transmission by blood transfusion remains theoretical since no single case of TT-CHKV has ever been published. CHKV was introduced to LATAM in 2013, hitting first the Saint Martin Island in the Caribbean, brought probably from the South
Pacific. The implicated CHKV Asian strain rapidly spread over the Caribbean and to South, Central, and North America (34). In the French West Indies, concerns about blood safety led to early implementation of a lab-developed NAT, in addition to pathogen reduction and quarantine (35). They were able to detect four viremic donors, two of them developed fever after donation and the other two remained asymptomatic. A large outbreak occurred a few months later in Puerto Rico with up to $2.1 \%$ of donors testing CHKV-RNA ${ }^{+}$(36). In contrast to the fast adoption of NAT for WNV, upon solid evidence of the clinical impact of TT-WNV, and for Zika, even lacking such parallel data, NAT for CHKV was never implemented in Puerto Rico.

From the Caribbean, the Asian strain spread first to the Northern countries of South America; Colombia, Venezuela, Suriname, Guyana, and the French overseas territory of French Guyana (37). The Brazilian Amazon state of Amapá, contiguous to the French Guyana, was the first to report autochthonous cases in September 2014. Curiously, at about the same time, an infected individual brought the East-South-Central Africa (ECSA) strain to the Northeastern state of Bahia, resulting in hundreds of cases and the establishment of this lineage as endemic in the region (38). In the following years, growing number of presumed CHKV cases were verified in Brazil, 38,499 in 2015, 271,824 in 2016 , and approximately 200,000 in 2017 , with dozens of deaths $(39,40)$. It is suspected that another arbovirus, Mayaro (MAYV), belonging to the same Alphavirus genus from the Togaviridae family, may be hidden among cases attributed to CHKV (41) and DENV (42).

There is a fear in LATAM in general, that huge outbreaks of $\mathrm{CHKV}$ will take place in the next years, since the majority of the population is still naïve to this virus. Strategies to mitigate the risk of TT-CHKV are not being actively discussed, since the risk of getting infected by mosquitoes is much higher and the associated clinical picture absolutely clear. In LATAM countries, with several social and health demands, it is debatable whether the resources to prevent a few TT-CHKV should not be invested in vector control, in order to benefit a larger number of inhabitants, including blood recipients that are off course also susceptible to mosquitoes' bites in daily life outside blood transfusion settings. However, availability of, in development, arboviral multiplex NATs allowing for simultaneous detection of Dengue, Chikungunya, and Zika and/ or pathogen reduction technologies acting on whole blood (43) or components, necessarily including red cells (44) may perhaps result in cost-effective measures to be implemented in endemic areas, home to the majority of the LATAM population.

\section{AUTHOR CONTRIBUTIONS}

The author confirms being the sole contributor of this work and approved it for publication.

\section{FUNDING}

This work was partially supported by São Paulo State Research Agency (FAPESP) Grant \# 2014/50093-8, and the grant CNPq 444961/2014-3. 


\section{REFERENCES}

1. Bruce-Chwatt LJ. Transfusion malaria. Bull WHO (1974) 50:337-46.

2. Stansbury LG, Hess JR. Blood transfusion in World War I: the roles of Lawrence Bruce Robertson and Oswald Hope Robertson in the "most important medical advance of the war". Transfus Med Rev (2009) 23:232-6. doi:10.1016/j.tmrv.2009.03.007

3. Perkins HA, Busch MP. Transfusion-associated infections: 50 years of relentless challenges and remarkable progress. Transfusion (2010) 50:2080-99. doi:10.1111/j.1537-2995.2010.02851.x

4. WHO/PAHO. Supply of Blood for Transfusion in Latin American and Caribbean Countries 2012 and 2013. Washington, DC: OPS (2015). Available from: http://www.who.int

5. de Almeida-Neto C, Goncalez TT, Birch RJ, de Carvalho SM, Capuani L, Leão SC, et al. Risk factors for human immunodeficiency virus infection among Brazilian blood donors: a multicentre case-control study using audio computer-assisted structured interviews. Vox Sang (2013) 105(2):91-9. doi:10.1111/vox.12028

6. Levi JE, Lira SM, Bub CB, Polite MB, Terzian CC, Kutner JM. Contrasting $\mathrm{HCV}$ and HIV seroepidemiology in 11 years of blood donors screening in Brazil. Transfus Med (2017) 27(4):286-91. doi:10.1111/tme.12427

7. Schmunis GA, Zicker F, Cruz JR, Cuchi P. Safety of blood supply for infectious diseases in Latin American countries, 1994-1997. Am J Trop Med Hyg (2001) 65(6):924-30. doi:10.4269/ajtmh.2001.65.924

8. Lye DC, Archuleta S, Syed-Omar SF, Low JG, Oh HM, Wei Y, et al. Prophylactic platelet transfusion plus supportive care versus supportive care alone in adults with dengue and thrombocytopenia: a multicentre, open-label, randomised, superiority trial. Lancet (2017) 389(10079):1611-8. doi:10.1016/S0140-6736(17)30269-6

9. Linnen JM, Vinelli E, Sabino EC, Tobler LH, Hyland C, Lee TH, et al. Dengue viremia in blood donors from Honduras, Brazil, and Australia. Transfusion (2008) 48:1355-62. doi:10.1111/j.1537-2995.2008.01772.x

10. Dias LL, Amarilla AA, Poloni TR, Covas DT, Aquino VH, Figueiredo LT. Detection of dengue virus in sera of Brazilian blood donors. Transfusion (2012) 52:1667-71. doi:10.1111/j.1537-2995.2012.03729.x

11. Sabino EC, Loureiro P, Lopes ME, Capuani L, McClure C, Chowdhury D, et al. Transfusion based transmission of dengue virus and associated clinical symptoms during the 2012 epidemic in Brazil. J Infect Dis (2016) 213:694-702. doi:10.1093/infdis/jiv326

12. Arellanos-Soto D, B-d Cruz V, Mendoza-Tavera N, Ramos-Jiménez J, CázaresTaméz R, Ortega-Soto A, et al. Constant risk of dengue virus infection by blood transfusion in an endemic area in Mexico. Transfus Med (2015) 25(2):122-4. doi:10.1111/tme. 12198

13. Stramer SL, Linnen JM, Carrick JM, Foster GA, Krysztof DE, Zou S, et al. Dengue viremia in blood donors identified by RNA and detection of dengue transfusion transmission during the 2007 dengue outbreak in Puerto Rico. Transfusion (2012) 52:1657-66. doi:10.1111/j.1537-2995.2012.03566.x

14. Levi JE. Dengue virus and blood transfusion. J Infect Dis (2016) 213:689-90. doi:10.1093/infdis/jiv322

15. Levi JE, Nishiya A, Félix AC, Salles NA, Sampaio LR, Hangai F, et al. Realtime symptomatic case of transfusion-transmitted dengue. Transfusion (2015) 55:961-4. doi:10.1111/trf.12944

16. Matos D, Tomashek KM, Perez-Padilla J, Muñoz-Jordán J, Hunsperger E, Horiuchi K, et al. Probable and possible transfusion-transmitted dengue associated with NS1 antigen-negative but RNA confirmed-positive red blood cells. Transfusion (2016) 56(1):215-22. doi:10.1111/trf.13288

17. Pealer LN, Marfin AA, Petersen LR, Lanciotti RS, Page PL, Stramer SL, et al. Transmission of West Nile virus through blood transfusion in the United States in 2002. West Nile Virus Transmission Investigation Team. N Engl J Med (2003) 349:1236-45. doi:10.1056/NEJMoa030969

18. Dodd RY, Foster GA, Stramer SL. Keeping blood transfusion safe from West Nile virus: American Red Cross experience, 2003 to 2012. Transfus Med Rev (2015) 29:153-61. doi:10.1016/j.tmrv.2015.03.001

19. Elizondo-Quiroga D, Elizondo-Quiroga A. West Nile virus and its theories, a big puzzle in Mexico and Latin America. J Glob Infect Dis (2013) 5(4):168-75. doi:10.4103/0974-777X.122014

20. Hills SL, Fischer M, Petersen LR. Epidemiology of Zika virus Infection. J Infect Dis (2017) 216(Suppl_10):S868-74. doi:10.1093/infdis/jix434
21. Musso D, Bossin H, Mallet HP, Besnard M, Broult J, Baudouin L, et al Zika virus in French Polynesia 2013-14: anatomy of a completed outbreak. Lancet Infect Dis (2017). doi:10.1016/S1473-3099(17)30446-2

22. de Araújo TVB, Rodrigues LC, de Alencar Ximenes RA, de Barros MirandaFilho D, Montarroyos UR, de Melo APL, et al. Association between Zika virus infection and microcephaly in Brazil, January to May, 2016: preliminary report of a case-control study. Lancet Infect Dis (2016) 16:1356-63. doi:10.1016/S1473-3099(16)30318-8

23. Bierlaire D, Mauguin S, Broult J, Musso D. Zika virus and blood transfusion: the experience of French Polynesia. Transfusion (2017) 57:729-33. doi:10.1111/trf. 14028

24. Barjas-Castro ML, Angerami RN, Cunha MS, Suzuki A, Nogueira JS, Rocco IM, et al. Probable transfusion-transmitted Zika virus in Brazil. Transfusion (2016) 56:1684-8. doi:10.1111/trf.13681

25. Motta IJ, Spencer BR, Cordeiro da Silva SG, Arruda MB, Dobbin JA, Gonzaga YBM, et al. Evidence for transmission of Zika virus by platelet transfusion. N Engl J Med (2016) 375:1101-3. doi:10.1056/ NEJMc1607262

26. Stone M, Lanteri MC, Bakkour S, Deng X, Galel SA, Linnen JM, et al. Relative analytical sensitivity of donor nucleic acid amplification technology screening and diagnostic real-time polymerase chain reaction assays for detection of Zika virus RNA. Transfusion (2017) 57:734-47. doi:10.1111/ trf.14031

27. Gallian P, Cabié A, Richard P, Paturel L, Charrel RN, Pastorino B, et al. Zika virus in asymptomatic blood donors in Martinique. Blood (2017) 129(2):263-6. doi:10.1182/blood-2016-09-737981

28. Musso D, Stramer SL; AABB Transfusion-Transmitted Diseases Committee, Busch MP; International Society of Blood Transfusion Working Party on Transfusion-Transmitted Infectious Diseases. Zika virus: a new challenge for blood transfusion. Lancet (2016) 387(10032):1993-4. doi:10.1016/ S0140-6736(16)30428-7

29. WHO. Interim Guidance. Maintaining a Safe and Adequate Blood Supply during Zika Virus Outbreaks. (2016). WHO/ZIKV/HS/16.1. Available from: http://www.who.int

30. Adams L, Bello-Pagan M, Lozier M, Ryff KR, Espinet C, Torres J, et al. Update: ongoing Zika virus transmission-Puerto Rico, November 1, 2015 July 7, 2016. MMWR Morb Mortal Wkly Rep (2016) 65:774-9.

31. Williamson PC, Linnen JM, Kessler DA, Shaz BH, Kamel H, Vassallo RR, et al. First cases of Zika virus-infected US blood donors outside states with areas of active transmission. Transfusion (2017) 57:770-8. doi:10.1111/ trf. 14041

32. Galel SA, Williamson PC, Busch MP, Stanek D, Bakkour S, Stone M, et al. First Zika-positive donations in the continental United States. Transfusion (2017) 57:762-9. doi:10.1111/trf.14029

33. Netto EM, Moreira-Soto A, Pedroso C, Höser C, Funk S, Kucharski AJ, et al. High Zika virus seroprevalence in Salvador, northeastern Brazil limits the potential for further outbreaks. MBio (2017) 8:e1390-1317. doi:10.1128/ mBio.01390-17

34. Chen R, Puri V, Fedorova N, Lin D, Hari KL, Jain R, et al. Comprehensive genome scale phylogenetic study provides new insights on the global expansion of chikungunya virus. J Virol (2016) 90(23):10600-11. doi:10.1128/ JVI.01166-16

35. Gallian P, de Lamballerie X, Salez N, Piorkowski G, Richard P, Paturel L, et al. Prospective detection of chikungunya virus in blood donors, Caribbean 2014. Blood (2014) 123:3679-81. doi:10.1182/blood-2014-03-564880

36. Simmons G, Brès V, Lu K, Liss NM, Brambilla DJ, Ryff KR, et al. High incidence of chikungunya virus and frequency of viremic blood donations during epidemic, Puerto Rico, USA, 2014. Emerg Infect Dis (2016) 22(7):1221-8. doi:10.3201/eid2207.160116

37. Bajak A. US assesses virus of the Caribbean. Nature (2014) 152:124-5. doi:10.1038/512124a

38. Nunes MR, Faria NR, de Vasconcelos JM, Golding N, Kraemer MU, de Oliveira LF, et al. Emergence and potential for spread of chikungunya virus in Brazil. BMC Med (2015) 13:102. doi:10.1186/s12916-0150348-x

39. BRAZIL. Boletim Epidemiológico: Monitoramento dos casos de dengue, febre de chikungunya e febre pelo vírus Zika até a Semana Epidemiológica. (2017). Available from: http://portalsaude.saude.gov.br 
40. Brito CA. Alert: severe cases and deaths associated with chikungunya in Brazil. Rev Soc Bras Med Trop (2017) 50(5):585-9. doi:10.1590/0037-86820479-2016

41. Esposito DLA, Fonseca BALD. Will Mayaro virus be responsible for the next outbreak of an arthropod-borne virus in Brazil? Braz J Infect Dis (2017) 21(5):540-4. doi:10.1016/j.bjid.2017.06.002

42. Zuchi N, Heinen LB, Santos MA, Pereira FC, Slhessarenko RD. Molecular detection of Mayaro virus during a dengue outbreak in the state of Mato Grosso, Central-West Brazil. Mem Inst Oswaldo Cruz (2014) 109:820-3. doi:10.1590/0074-0276140108

43. Allain JP, Goodrich R. Pathogen reduction of whole blood: utility and feasibility. Transfus Med (2017) 27(Suppl 5):320-6. doi:10.1111/tme.12456

44. Aubry M, Laughhunn A, Santa Maria F, Lanteri MC, Stassinopoulos A, Musso D. Amustaline (S-303) treatment inactivates high levels of chikungunya virus in red-blood-cell components. Vox Sang (2018). doi:10.1111/vox. 12626

Conflict of Interest Statement: The author declares that the research was conducted in the absence of any commercial or financial relationships that could be construed as a potential conflict of interest.

Copyright (c) 2018 Levi. This is an open-access article distributed under the terms of the Creative Commons Attribution License (CC BY). The use, distribution or reproduction in other forums is permitted, provided the original author(s) and the copyright owner are credited and that the original publication in this journal is cited, in accordance with accepted academic practice. No use, distribution or reproduction is permitted which does not comply with these terms. 